\title{
C. Practical and Therapeutic Values of Correspondence Study
}

\author{
Berenice H. Lee
}

$\mathrm{I}$ F correspondence study as a means of education needed justification beyond the fact that it is elected, not required, that it is the hard way of acquiring formal knowledge instead of the easier way provided by classtoom participation, the uses to which it is put by patients in tuberculosis sanatoria, hospitals, prisons, and reformatories would be reason enough for providing the very best services that could be provided for those adults who elect courses for socalled "home study." In addition to those persons who are in institutions of this sort, there are the adults and high-school-level students who are confined to their homes as the result of poliomyelitis and accidents, and the paraplegics and spastics who are limited in their activities.

The vocational rehabilitation program is carried on in the state of Michigan under the Department of Public Instruction, centered at the capitol in Lansing. Through this program, patients in hospitals and sanatoria and those still being cared for in their homes after release from such institutions may continue without cost their work toward a college degree, toward a high-school diploma, or toward preparing themselves for a vocation that can be of use to them when they regain their health. The state penal instit utions are not provided with similar financial support from the state, so those men who wish to study through correspondence must pay the enrollment fees and purchase their books themselves, unless they are eligible to benefits under the G. I. Bill.

The University of Michigan has provided correspondence study services for patients in twenty-six different sanatoria, and has also provided services for the State Prison at Jackson, Ionia Reformatory, the Federal Prison at Milan, ar $\mathbf{1} \mathbf{t}^{2}$. Cassidy Lake Technical Training School. Approximately one hundrod students have been enrolled from these institutions during the past twelve-month period. In the past there have been fewer students from these institutions, but since World War II approximately 800 veterans have been sentenced to prison in Michigan, and many of the $m$ have started work under the G. I. Bill.

Berenice H. Lee is Supervis or of Correspondence Study at the University of Michigan, Ann Arbor, Michigan. 
The enrollments from sanatoria have increased also since the conclusion of World War II because of the increased number of tubercular veterans.

Among those veterans, one case will serve to illustrate the values attached to the use of correspondence study for hospitalized patients. A twenty-eight-year-old student was withdrawn from the campus two months after he had started his senior year and sent to a veterans hospital, then to the University Hospital, and, finally, to Howell Sanatorium. For two and a half years he spent his life on a Stryker frame. During this time, he worked on correspondence study courses. In the middle of March, 1952, he completed the last of twenty-one hours of college work through this means. The usual requirements for the acquisition of a degree from the University of Michigan regarding residence on campus for the last year were waived and he fulfilled through correspondence study all of the academic requirements that would allow him to receive his degree in June, 1952. While other graduating students were receiving their sheepskins in the immense stadium of the University of Michigan, the supervisor of the correspondence study department presented to this young $m$ an in person the engraved diploma that he had earned under such difficult circumstances. His case is outstanding and has a dramatic element to it, but others without any more immediate hope for a normal life are profiting in the same way and being helped to feel that they are still a part of society, even though they are temporarily isolated.

The role of this method of study in penal institutions is on a much smaller scale, with an enrollment during the past twelve-month period of approximately fifty students. The election of college-level credit courses is higher than the election of high-school-level courses. During the past year, two of the students have been released to civilian life and one of them is continuing his high-school work through correspondence study as a means of procuring his diploma, a requisite to advancement in his field of work. This student is a man thirtyseven years old, a former member of the Marine Corps of World War II, who had spent eleven years in prison. During that time, he had completed seven courses toward his high-school diploma. He has taken one additional course since his release.

It is the firm conviction of the supervisor of correspondence study of the University of Michigan that there is no justification to the contention of some that it is "too much trouble to bother with" the restrictions of the G. I. Bill, the details of the billing and delays entailed with state rehabilitation programs, and with the slow and sometimes painful retums on the part of those handicapped enrollees 
in correspondence study courses. Rather, we should examine our aims and our product in the way of services rendered to those who can use them. We are not competing with other educational institutions nor are we attempting to build up a "business"; we are attempting to augment the educational programs for the benefit of those who cannot avail themselves of classroom activities. Ours is a unique service not duplicated at present in any other form. It is a means whereby men and women may continue their education toward a successful participation in life. The therapeutic value attached to such work cannot be measured, particularly for those for whom there is little hope of eventual recovery.

\section{HELP FOR THE TEACHER}

A use often made of supervised correspondence study syllabi is that of helping teachers in the classroom. There are many beginning teachers who have had little, if any, experience in organizing a course of instruction. Particularly in the small school, teachers are frequently called upon to teach subjects in which they have had a minimum of preparation. Other teachers are asked to teach subjects which they have not studied for many years. Still others are teaching on emergency certificates and lack adequate preparation for the work they do. There are also teachers who teach so many classes that they have no time in which to organize their work properly.

In all of the above cases, correspondence study materials can be of assistance. A carefully prepared correspondence course provides a form of organization which the teacher can adapt to her own needs. It need not, and in most cases should not, be slavishly followed, but it will give to the overburdened or inadequately prepared teacher the sense of security which comes from having something definite about which to plan and to build. The principal himself is often so busy that he has inadequate time in which to help teachers plan and organize their courses to the extent that this needs to be done. The use of supervised correspondence study syllabi will help him as well as the teacher or teachers involved.

Correspondence study courses may be purchased at a very nominal price where teaching service is not required of the correspondence center.-University of Nebraska Extension Division, Lincoln, Nebraska. 